University of Nebraska - Lincoln

DigitalCommons@University of Nebraska - Lincoln

Sociology Department, Faculty Publications

Sociology, Department of

$8-2020$

\title{
Educational Benefits and Cognitive Health Life Expectancies: Racial/Ethnic, Nativity, and Gender Disparities
}

\author{
Marc A. Garcia \\ University of Nebraska - Lincoln, marcagarcia@unl.edu \\ Brian Downer \\ University of Texas Medical Branch, brdowner@utmb.edu \\ Chi-Tsun Chiu \\ Academia Sinica, Taipei, Taiwan, ctchiu@gate.sinica.edu.tw \\ Joseph L. Saenz \\ University of Southern California, Davis School of Gerontology, saenzj@usc.edu \\ Kasim Ortiz \\ University of New Mexico, kortiz5@unm.edu
}

See next page for additional authors

Follow this and additional works at: https://digitalcommons.unl.edu/sociologyfacpub

Part of the Family, Life Course, and Society Commons, and the Social Psychology and Interaction

Commons

Garcia, Marc A.; Downer, Brian; Chiu, Chi-Tsun; Saenz, Joseph L.; Ortiz, Kasim; and Wong, Rebeca, "Educational Benefits and Cognitive Health Life Expectancies: Racial/Ethnic, Nativity, and Gender Disparities" (2020). Sociology Department, Faculty Publications. 728.

https://digitalcommons.unl.edu/sociologyfacpub/728

This Article is brought to you for free and open access by the Sociology, Department of at DigitalCommons@University of Nebraska - Lincoln. It has been accepted for inclusion in Sociology Department, Faculty Publications by an authorized administrator of DigitalCommons@University of Nebraska - Lincoln. 


\section{Authors}

Marc A. Garcia, Brian Downer, Chi-Tsun Chiu, Joseph L. Saenz, Kasim Ortiz, and Rebeca Wong 
Educational Benefits and Cognitive Health Life Expectancies: Racial/Ethnic, Nativity, and Gender Disparities

Marc A. Garcia, $\mathrm{PhD}^{1}$, Brian Downer, $\mathrm{PhD}^{2}$, Chi-Tsun Chiu, $\mathrm{PhD}^{3}$, Joseph L. Saenz, $\mathrm{PhD}^{4}$, Kasim Ortiz, $\mathrm{MS}^{5}$, Rebeca Wong, $\mathrm{PhD}^{6}$

1. Department of Sociology and Institute for Ethnic Studies, University of Nebraska-Lincoln, Lincoln, Nebraska

2. Division of Rehabilitation Sciences, University of Texas Medical Branch, Galveston, Texas

3. Institute of European and American Studies, Academia Sinica, Taipei, Taiwan

4. University of Southern California, Davis School of Gerontology, Los Angeles, California

5. University of New Mexico, Department of Sociology \& Criminology, Albuquerque, New Mexico

6. University of Texas Medical Branch, Department of Preventive Medicine and Population Health, Galveston, Texas

*Address correspondence to: Marc A. Garcia, PhD, University of Nebraska, Sociology \& Institute of Ethnic Studies, 704 Oldfather Hall, Lincoln, NE 68588-0324. E-mail: marcagarcia@unl.edu

Gerontologist. 2020 Aug 24:gnaa112.

doi: 10.1093/geront/gnaa112.

Online ahead of print.

PMID: 32833008

(C) The Author(s) 2020. Published by Oxford University Press on behalf of The

Gerontological Society of America. All rights reserved. For permissions, please e-mail:

journals.permissions@oup.com. 


\section{Funding:}

We gratefully acknowledge financial support for this research provided by the National Institute on Aging (T32AG000270, T32AG000037, R01AG054466-0S1, R00AG058799, K01AG058789, P30 AG059300, and P30AG043073), the National Institute on Minority Health and Health Disparities Research (U54MD004811-0S1), the National Institute of Nursing Research (R01NR015241-0S1), and the Nebraska Tobacco Settlement Biomedical Research Development Funds.

Conflict of Interest: The authors declare no conflict of interest. 


\begin{abstract}
Background and Objectives: To examine racial/ethnic, nativity, and gender differences in the benefits of educational attainment on cognitive life expectancies among older adults in the United States.

Design and Methods: We used data from the Health and Retirement Study (1998-2014) to estimate Sullivan-based life tables of cognitively healthy, cognitively impaired/no dementia (CIND), and dementia life expectancies by gender for older White, Black, U.S.-born and foreign-born Hispanic adults with less than high school, high school, and some college or more.

Results: White respondents lived a greater percentage of their remaining lives cognitive healthy than their minority Black or Hispanic counterparts, regardless of level of education. Among respondents with some college or more, versus less than high school, Black and U.S.-born Hispanic women exhibited the greatest increase (both 37 percentage points higher) in the proportion of total life expectancy spent cognitively healthy; whereas White women had the smallest increase (17 percentage points higher). For men, the difference between respondents with some college or more, versus less than high school, was greatest for Black men (35 percentage points higher) and was lowest for U.S.born Hispanic men (21 percentage points higher).

Discussion and Implications: Our results provide evidence that the benefits of education on cognitive life expectancies are largest for Black men and women, and U.S.-born Hispanic women. The combination of extended longevity and rising prevalence of Alzheimer's disease point to the need for understanding why certain individuals spend an extended period of their lives with poor cognitive health.
\end{abstract}

Keywords: Cognitive Impairment; Dementia; Life Expectancy; Race/Ethnicity; Nativity 


\section{Introduction}

The rising prevalence of Alzheimer's disease and related dementias (ADRD) has led to increased interest in using cognitive health life expectancies to capture the population-level burden of ADRD (Ashby-Mitchell, Jagger, Fouweather, \& Anstey, 2015; Crimmins, Saito, \& Kim, 2016; Crimmins \& Zhang, 2019; Crimmins et al., 2018). Cognitive health life expectancies provide a reliable assessment of the burden of cognitive loss in a population by highlighting whether additional years lived are spent cognitively healthy or in poor cognitive health.

There are no effective treatments for ADRD. However, mounting evidence indicates that targeting potentially modifiable risk factors, such as educational attainment, can delay the onset of developing ADRD (Peterson, Fain, A. Butler, Ehiri, \& Carvajal, 2020), which is important for reducing the future prevalence of ADRD (Zissimopoulos, Tysinger, St. Clair, \& Crimmins, 2018). As the older population in the United States becomes more racially and ethnically diverse, educational disparities will play an even more critical role in shaping the prevalence of ADRD.

Several epidemiological studies have shown associations between higher educational attainment and better cognitive functioning (Garcia, Saenz, Downer, \& Wong, 2018; Garcia et al., 2020; Meng \& D'arcy, 2012; Soldan et al., 2017), living a greater number of years cognitively healthy (Crimmins et al., 2018; Farina, Hayward, Kim, \& Crimmins, 2019; Lievre, Alley, \& Crimmins, 2008; Robitaille et al., 2018), and lower risk for ADRD (Caamaño-Isorna, Corral, Montes-Martínez, \& Takkouche, 2006; Stern, 2012). The cognitive reserve hypothesis is a leading theory to explain the association between educational attainment and ADRD (Peterson et al., 2020; Serra, Caltagirone, \& Bozzali, 2017). Cognitive reserve consists of individual differences in susceptibility to age-related brain damage or ADRD-related pathology (Stern, 2012; Stern et al., 2018). Biologically, cognitive reserve increases the efficacy of existing neural brain networks by enhancing the brain's ability to recruit additional networks when completing tasks, positively shaping cognitive functioning (Steffener, Reuben, Rakitin, \& Stern, 2011; 
Stern, 2009). More nuanced perspectives regarding cognitive reserve highlight the compensatory approaches the brain develops, resulting from early- and mid-life experiences such as educational attainment and occupation (Stern, 2002). Hence, older adults with higher cognitive reserve are able to maintain healthy cognitive functioning despite aging-related damage to the brain (Stern, 2017).

According to the cognitive reserve hypothesis, educational attainment may also reduce the risk of ADRD by optimizing cognitive functioning earlier in life, allowing older adults to experience cognitive decline for a longer period before reaching clinical and diagnostic thresholds for ADRD. Supportive evidence suggests two key elements. First, greater educational attainment is associated with higher cognitive functioning but not slower cognitive decline among older adults without ADRD (Gross et al., 2015; Zahodne et al., 2011). Second, highly educated older adults spend a greater proportion of their remaining life cognitively healthy compared to less educated older adults (Crimmins et al., 2018; Lievre et al., 2008; Robitaille et al., 2018).

Although increases in educational attainment among older adults in the United States has been a key driver in the growth of individuals living a greater number of years cognitively healthy (Crimmins et al., 2018; Robitaille et al., 2018), significant racial/ethnic disparities remain in both educational attainment and cognitive health life expectancies (Garcia et al., 2019; U.S. Census Bureau, 2019). Indeed, recent findings on racial and educational disparities in dementia life expectancies document that older non-Hispanic Black (hereafter, Black) adults spend significantly more years after age 65 with dementia than non-Hispanic White (hereafter, White) adults, regardless of educational attainment level (Farina et al., 2019). These findings provide evidence that racial disparities in dementia life expectancy persist across educational gradients. In addition, recent evidence from a systematic review on modifiable risk factors for several cognitive outcomes indicate that educational attainment provided the strongest evidence for explaining racial disparities in cognitive aging (Peterson et al., 2020). These studies 
highlight the important contribution of sociodemographic factors to the cognitive health and well-being of the older U.S. population.

While educational differentials in cognitive health life expectancies among the general population aged 65 and older are well documented (Crimmins et al., 2018; Lievre et al., 2008; Robitaille et al., 2018), it remains unclear whether educational attainment disparities in cognitive health life expectancies vary among older White, Black, and Hispanic adults. Recent research on cognitive reserve theory led us to develop the following hypotheses: 1) we hypothesize that the protective effect of educational attainment on shaping cognitive health life expectancies will be greater for older Black and Hispanic adults than older White adults; and 2) we hypothesize that the protective effect of educational attainment on cognitive health life expectancies will be greater for older foreign-born Hispanic adults than older U.S.-born Hispanic adults. These hypotheses are further motivated by research showing the educational gradient for cognition is greater for individuals from disadvantaged and marginalized backgrounds (Brand \& Xie, 2010; Farina et al., 2019; Jean et al., 2019).

The current study aims to provide a comprehensive examination of cognitive health life expectancies by educational attainment for older White, Black, and Hispanic adults. We build on prior studies by examining cognitive disparities across and within educational attainment categories. Additionally, we focus on two distinct stages of the life course that encompass mid-life (50 and older) and late-life (65 and older), to better capture population variability across the lifespan. Given that educational attainment and overall life expectancy vary by nativity and gender, we further explore how these associations interact with race/ethnicity to shape cognitive health expectancies. 


\section{Methods}

Data

This study used data from the Health and Retirement Study (HRS) (Sonnega et al., 2014) and the public-use National Health Interview Survey Linked Mortality Files (NHIS-LMF) (Blewett, Rivera Drew, King, \& Williams, 2019). The NHIS-LMF (1999-2014) provides mortality follow-up from the National Death Index through December 31, 2015. We used the NHIS-LMF for mortality due to the small number of deaths reported among older Hispanic adults in the HRS. Prior research indicates that mortality linkages for older Hispanics in the NHIS-LMF are highly accurate (Lariscy, Hummer, \& Hayward, 2015) and racial/ethnic life expectancies using these data (Cantu, Hayward, Hummer, \& Chiu, 2013; Garcia et al., 2019) closely resemble life tables reported by the National Center for Health Statistics (Arias \& Xu, 2019). Therefore, we used the NHIS-LMF to obtain mortality incidence and pooled data from the HRS (1998-2014) to obtain cognitive impairment prevalence to construct cognitive health life expectancies by race/ethnicity, nativity, gender, and educational attainment. These estimates are nationally representative of the noninstitutionalized population aged 50 and older in the United States. More in-depth methodological descriptions for each data source are published elsewhere (Hauser \& Willis, 2004; NCHS, 2018). After omitting respondents who identify as "other" and those with missing values on nativity status $(\mathrm{N}=888)$, and educational attainment $(\mathrm{N}=90)$ our final analytic sample from the HRS included 31,242 unique individuals who contributed 163,912 age-specific observations. For NHIS-LMF, we exclude respondents missing nativity status $(\mathrm{N}=355)$, and retained respondents who self-identified as U.S.-born non-Hispanic White, U.S.-born non-Hispanic Black, U.S.-born Hispanic, and foreign-born Hispanic adults ( $\mathrm{N}=45,087$ excluded). The final analytic sample for mortality analysis from the NHISLMF is $443,103$. 


\section{Measures}

Cognition in the HRS is assessed using a modified version of the Telephone Interview for Cognitive Status (TICS-M) for participants able to complete a direct interview (Brandt, Spencer, \& Folstein, 1988). The TICS-M includes the immediate and delayed recall of a 10-word list, Serial 7s subtraction, and a backwards counting task (Crimmins, Kim, Langa, \& Weir, 2011). The total score ranges from 0 to 27 points with higher scores reflecting better cognitive functioning. Respondents with scores of 12 or above were classified as cognitive healthy; 7-11 as CIND; and 6 or below as having dementia (Cabeza, Anderson, Locantore, \& McIntosh, 2002). Cognitive status for respondents unable to complete a direct interview was ascertained by three proxy interview questions: proxy-reported memory rated as excellent (0-points) to poor (4-points); number of instrumental activities of daily living limitations (0-5); and an interviewer assessment of difficulty completing the interview due to cognitive limitation (none 0-points, some 1-point, prevented 2-points). Proxies with scores of 2 or below were categorized as cognitively healthy; 3-5 as CIND; and 6 or above as dementia (Crimmins et al., 2011).

\section{Covariates}

Covariates included in our analysis were race/ethnicity, nativity, gender, age, and educational attainment. Race/ethnicity, nativity, and education were self-reported. We included U.S.-born White, U.S.-born Black, U.S.-born Hispanic, and foreign-born Hispanic adults. Asians and other racial/ethnic groups were omitted due to small sample size. Gender corresponded to whether the respondent identified as a woman or man. We categorized education as less than high school (0-11 years), high school degree, and some college or more (13+ years). 


\section{Statistical Analysis}

We conducted our analyses in two steps. First, we generated descriptive statistics to characterize the sample population. Comparisons across age, educational attainment, and cognitive statuses were conducted using t-tests to assess differences in continuously measured indicators and chi-square tests to assess group differences over categorical indicators by race/ethnicity, nativity, and gender.

Second, we modeled cognitive health life expectancies. Cognitive health life expectancy refers to the number of years an individual can expect to live cognitively healthy (Dubois \& Hebert, 2006). Healthy life expectancy calculated by the Sullivan method is an appealing approach for comparing groups with different age distributions, as it takes into account age-specific prevalence of health conditions and age-specific mortality risks (Jagger, Van Oyen, \& Robine, 2014). We integrated age-specific CIND and dementia prevalence from the HRS with age-specific mortality information from the NHIS-LMF to calculate Sullivan life table models of cognitively healthy, CIND, and dementia life expectancy for each racial/ethnic and nativity group by educational attainment category and gender (Sullivan, 1971). We used multinomial logistic regression models to estimate the prevalence with sampling weights provided by the HRS. Respondents who transitioned from living in the community to a nursing home were assigned a weighted value of zero (Chien et al., 2015). Gompertz hazard models and sampling weights from the NHIS-LMF were used to estimate the mortality rates for total life expectancy (Shkolnikov, Jdanov, Andreev, \& Vaupel, 2011). This method divides total life expectancy into different health states based on the age-specific prevalence of each cognitive state (cognitively healthy, CIND, and dementia).

A weighted bootstrapping technique was used to obtain standard errors by resampling our analytic sample. This allowed us to estimate sampling variability for the life table functions and life expectancies. Based on 300 bootstrap samples, 95\% empirical intervals (EI) were obtained from the 2.5th to the 97.5th percentile of the simulated distributions of each cognitive state to test for significant differences across educational attainment categories. We also obtained 95\% EI of cognitive health life 


\section{Results}

Descriptive Statistics

Table 1 shows the sample characteristics of the study population. White respondents were significantly older, more educated, and had a lower prevalence of CIND and dementia than Black and Hispanic respondents, regardless of gender. Overall, women were older and less educated than men across all racial/ethnic groups; except for Black women who exhibited higher educational attainment than Black men. Furthermore, the prevalence of CIND for men and women varied largely by race/ethnicity and nativity, with White and Black women exhibiting lower CIND rates than men. In contrast, U.S.-born Hispanic and foreign-born Hispanic women had higher rates of CIND than U.S.-born Hispanic and foreign-born Hispanic men. Finally, all women reported a higher prevalence of dementia than men, regardless of race/ethnicity and nativity. 
Table 1 about here

\title{
Cognitive Health Life Expectancies
}

\author{
Total Life Expectancy
}

Tables 2 and 3 present Sullivan life expectancy estimates of total, cognitively healthy, CIND, dementia, and the ratio cognitively healthy across educational attainment categories for men and women, respectively. At age 50, greater educational attainment was associated with increased total life expectancy for all respondents. Increases for men and women were greatest among older White adults with some college education (6.7 years for men and 6.5 years for women), and lowest for older foreign-born Hispanic adults with a high school degree (2.2 years for men and 1.1 years for women).

\section{Cognitive Health Life Expectancies Across Education Categories}

Cognitive health life expectancy was significantly higher among respondents with more education. Those with high school, and some college or more education, can expect to spend significantly more years cognitively healthy than individuals with less than a high school education. This advantage was greater among respondents with some college or more education. At age 50, men (women) with some college or more can expect to spend between 9.4 years and 12.3 years (10.6 years and 15.5 years) more cognitively healthy than their counterparts with less than a high school degree.

\section{Table 2 about here}

In contrast, men (women) with less than high school education can expect to spend between 3.9 years and 5.8 years (3.0 years and 5.9 years) more with CIND; and between 0.01 years and 3.2 years (1.1 years and 5.8 years) more with dementia compared to those with some college or more education. Men (women) with some college or more can expect to spend between $74 \%$ and $89 \%$ (72\% and $88 \%$ ) of their remaining years after age 50 cognitively healthy. Conversely, men (women) with less than a high school 
education can expect to spend between $42 \%$ and $64 \%$ (39\% and $71 \%$ ) of their remaining years after age 50 cognitively healthy.

Table 3 about here

\section{Cognitive Health Life Expectancies Within Education Categories}

Figures 1 and 2, which are based on results from Supplementary Tables 3 and 4, illustrate results for within educational attainment category comparisons in cognitively healthy life expectancies by racial/ethnic and nativity group. Our findings show significant racial/ethnic disparities in cognitive healthy life expectancies at age 50 within all education categories. These disparities were greatest between older Black and White adults. Among older Black adults with less than a high school education, men (women) can expect to spend 6.1 years (9.5 years) less cognitively healthy than their White counterparts. Similarly, older Hispanic women with less than a high school education can expect to spend nearly 5 fewer years cognitively healthy compared to older White women, regardless of nativity (Figure 1). U.S.-born Hispanic men with less than a high school education also spend significantly less time (1.8 years) cognitively healthy than White men with less than a high school education. In contrast, foreignborn-Hispanic men with less than a high school education did not significantly differ from White men. Racial/ethnic disparities in cognitive healthy life expectancies among those with a high school education largely mirrored the results above; however, foreign-born Hispanic women with a high school education no longer significantly differed from their White counterparts in time spent cognitively healthy. In contrast, having some college or more reduced the disparity between U.S.-born Hispanic and White women to non-significance.

Results for CIND and dementia life expectancies showed consistent racial/ethnic and nativity disparities within all educational attainment categories. Among those with less than a high school education, older foreign-born Hispanic adults were the most disadvantaged in the number of years 
expected to spend with CIND and dementia. Foreign-born Hispanic men (women) with less than a high school education can expect to spend 3.9 years (6.2 years) more with CIND and 2.3 years (5.3 years) more with dementia than their White counterparts. Black and U.S.-born Hispanic men (women) with less than a high school education can expect to spend 2.6 years and 2.2 years (5.2 years and 4.5 years) more with CIND and 2.4 years and 2.1 years (3.3 years and 4.0 years) more with dementia, respectively, compared to White men (Figures 1-2 and Supplementary Tables 3-4).

For those with a high school education, Black women and U.S.-born Hispanic men were the most disadvantaged in CIND (4.2 years and 4.1 years, respectively) and dementia life expectancies (1.9 years and 2.5 years, respectively) relative to their White counterparts. Having a high school education reduced disparities in dementia life expectancy between Hispanic and White women to non-significance, regardless of nativity. Similar results were observed among foreign-born Hispanic men with a high school education compared to White men. However, a slightly different pattern emerged for respondents with some college or more education. Foreign-born Hispanic women were the most disadvantaged group and can expect to spend more years with CIND and dementia than White women (3.9 years and 2.3 years, respectively), whereas U.S.-born Hispanic women did not significantly differ from White women in CIND and dementia life expectancies. Among men, older Black adults exhibited the greatest disparity in expected years spent with CIND (2.7 years) and older U.S.-born Hispanic men exhibited the greatest disparity in expected years spent with dementia (3.4 years) relative to older White men.

The above findings indicate that older Black and Hispanic adults can expect to spend a significantly smaller proportion of their remaining years after age 50 cognitively healthy relative to older White adults. Differences between older White and Black adults in the proportion of late life spent cognitively healthy were greatest among those with less than a high school education $(22 \%$ for men and $32 \%$ for women). Racial/ethnic and nativity differences for those with a high school education were largely similar except for a widening disparity between older U.S.-born Hispanic and White men. 
However, racial/ethnic and nativity disparities among those with some college or more education varied by gender. Foreign-born Hispanic women and U.S-born Hispanic men exhibited the largest disparity in the proportion of late life years spent cognitively healthy relative to their White counterparts (13\% and 15\%, respectively). In contrast, foreign-born Hispanic men and U.S-born Hispanic women exhibit the smallest disparities in proportion of years after age 50 cognitively healthy (9\% and 3\%, respectively) compared to White men and women.

Finally, our supplementary results for adults age 65 and older largely mirror the findings reported above. Notable exceptions for racial/ethnic and nativity differences in cognitive healthy life expectancies include Black (foreign-born Hispanic) men with college or more education no longer significantly differing from White men in dementia (CIND and proportion cognitively healthy) life expectancy. Similar patterns were observed for U.S.-born (foreign-born) Hispanic women with a high school education in cognitively healthy and CIND (CIND and proportion cognitively healthy) life expectancy.

\section{Discussion}

This study adds to the current literature on cognitive aging by examining whether the association between educational attainment and cognitive health life expectancy varies by race/ethnicity, nativity, and gender. Consistent with previous research, we found large differences by educational attainment in cognitive health life expectancies (Crimmins et al., 2018; Lievre et al., 2008; Robitaille et al., 2018). Having a high school degree and some college or more, versus less than a high school education, was associated with increased total life expectancy and reductions in the length and proportion of life spent with CIND and dementia. Increases in total years lived and in the proportion of cognitively healthy life were largest for respondents with some college or more. In contrast, respondents with less than a high school education lived shorter lives and experienced the greatest lifetime burden of CIND and dementia. 
To assess the benefits of education across groups, we examined how much more cognitively healthy life may be obtained through improved education by race/ethnicity, nativity, and gender. We found that the benefits of educational attainment may be most salient among groups that exhibit larger increases by education in the proportion of remaining life that one can expect to live cognitively healthy. We hypothesized that the protective effects of educational attainment on cognitive health life expectancies would be greater for older Black and Hispanic adults than for older White adults and greater for older foreign-born Hispanic adults than for older U.S.-born Hispanic adults.

Among women, we found that increases in the proportion of total life expectancy spent cognitively healthy by educational attainment was greatest for older Black and U.S.-born Hispanic adults with some college or more, followed by foreign-born Hispanic and Black women with a high school degree. This finding indicates that the overall benefits of education on cognitive healthy life expectancies is largest for older Black and U.S.-born Hispanic women, somewhat less for older foreign-born Hispanic women, and least for White women, suggesting that education may matter the most for the cognitive health and aging of older Black and U.S.-born Hispanic women.

Among men, increases in the proportion of total life expectancy spent cognitively healthy by educational attainment were greatest for older Black adults with some college or more and older Blacks with a high school degree compared to other men. Our results also pointed to nativity differentials, with larger increases in the proportion of cognitive healthy life expectancy observed for older foreign-born Hispanic men compared to U.S -born Hispanic men. These findings suggest that older Black men experience the largest benefits for education in cognitively healthy life compared to other men. In contrast, U.S.-born Hispanic men experience the smallest benefits from having a high school degree, and some college or more, compared to all other men.

Our results build upon previous findings of differences in cognitive life expectancies by race/ethnicity, nativity (Garcia et al., 2019), educational attainment (Crimmins et al., 2018), and recent 
work combining race and educational attainment (Farina et al., 2019). We further highlight that minority and immigrant men and women do not reap the same cognitive rewards as their respective White counterparts despite all racial/ethnic, nativity groups exhibiting increases in total life expectancy and declines in the length and proportion of life spent with CIND and dementia with greater educational attainment. White men and women exhibited a greater proportion of remaining life expectancy cognitively healthy compared to their minority and immigrant counterparts, regardless of educational attainment level.

In addition, we observed large differences in the percentage of life expectancy spent cognitive healthy by education among older minority and immigrant adults. Persistent racial/ethnic differences in quality of education may reflect a pattern indicating that similar levels of educational attainment are not necessarily an equalizer with respect to cognitive functioning and healthy aging (McLaughlin, Kim, Li, \& Zhang, 2020). Indeed, racial disparities in cognitive functioning have been shown to be attenuated after controlling for measures of education quality (Manly, Jacobs, Touradji, Small, \& Stern, 2002) and educational quality and literacy have been suggested to explain approximately $29 \%$ of Black-White disparities in general cognitive ability (Sisco et al., 2014). Future research should seek to disentangle the impacts of quality of education and differential educational benefits across race/ethnicity in shaping cognitive trajectories and corresponding life expectancies.

Moreover, it is important to recognize that structural racism leads to large disparities in educational attainment and quality of education (Merolla \& Jackson, 2019), which in turn contribute to the differences in cognitive life expectancies revealed by our analysis. There is no biological basis for racial/ethnic differences in educational attainment, education quality, and health outcomes. Rather, race/ethnicity serve as proxies for U.S. stratification resulting from structural racism that shapes the social conditions and access to resources that can manifest in differences in cognitive functioning later in life (Gee \& Ford, 2011; Glymour \& Manly, 2008; Phelan \& Link, 2015). Furthermore, the extent to which 
Black adults may reap benefits from their educational attainment by securing quality jobs may be limited by discrimination in the labor market (Pager \& Shepherd, 2008). Several studies have shown that indicators of structural racism, such as residential segregation (Caunca et al., 2020) and state-level racial/ethnic inequalities in infant mortality rates (Gilsanz et al., 2019) are associated with poor cognitive outcomes. This emerging body of literature highlights how structural racism is a fundamental cause of health disparities (Bailey et al., 2017; Phelan \& Link, 2015), and cognitive health outcomes among older minority and immigrant adults in the United States.

Our results should be considered in the context of several limitations. First, the cognitive status of participants who completed a direct interview was determined using a brief cognitive screening instrument. It is possible that the cognitive status of some participants was incorrectly classified. Second, inadequate sample sizes prevented examination of other minority groups. A study of ADRD incidence among six racial and ethnic groups in the United States revealed that Asian-Americans had significantly lower age-adjusted incidence rates of ADRD than Whites, whereas these rates were significantly higher for Native American and Alaskan Natives (Mayeda, Glymour, Quesenberry, \& Whitmer, 2016). Third, we did not consider other variables that are correlated with education that have been associated with cognitive functioning in older age, such as occupation, income, and wealth. Future research should examine whether dynamics related to economic mobility, such as occupation, income, and wealth, synergistically interact with education in meaningful ways that consequently alter educational returns beneficial for healthy cognitive aging processes. Finally, respondents who transitioned into nursing homes were not included in the analysis, which may have resulted in underestimates of the years spent in poor cognitive health for certain groups. This underestimation could potentially vary by race/ethnicity, nativity, and gender, given the characteristics related to nursing home admission.

Despite these limitations, our findings present important evidence that the benefits of educational attainment on cognitive health life expectancies vary by race, ethnicity, nativity, and gender. Our findings 
also support the increasing need to address the inequity in both educational attainment and quality of education resulting from structural racism. In addition, differentials identified with respect to the significance of a high school degree across genders should be investigated further, particularly in terms of efforts aimed at minimizing racial/ethnic disparities in cognitive health life expectancies. The expected increase in racial/ethnic diversity in the United States underscores the importance of continued monitoring of disparities in cognitive healthy life expectancies, particularly as adults transition from midlife to late-life. 


\section{References}

Arias, E, \& Xu, J. (2019). United States Life Tables, 2017. National vital statistics reports: from the Centers for Disease Control and Prevention, National Center for Health Statistics, National Vital Statistics System, 66(4), 1.

Ashby-Mitchell, Kimberly, Jagger, Carol, Fouweather, Tony, \& Anstey, Kaarin J. (2015). Life Expectancy with and without Cognitive Impairment in Seven Latin American and Caribbean Countries. PLoS One, 10(3), e0121867. https://doi.org/10.1371/journal.pone.0121867

Bailey, Z. D., Krieger, N., Agenor, M., Graves, J., Linos, N., \& Bassett, M. T. (2017). Structural racism and health inequities in the USA: evidence and interventions. Lancet, 389(10077), 1453-1463. https://doi.org/10.1016/S0140-6736(17)30569-X

Blewett, Lynn A, Rivera Drew, Julia A, King, Miriam L, \& Williams, Kari CW. (2019). IPUMS Health Surveys: National Health Interview Survey. https://nhis.ipums.org/

Brand, J. E., \& Xie, Y. (2010). Who benefits most from college? Evidence for negative selection in heterogeneous economic returns to higher education. American Sociological Review, 75(2), 273-302. https://doi.org/10.1177/0003122410363567 
Brandt, J., Spencer, M., \& Folstein, M. (1988). The telephone interview for cognitive status. Neuropsychiatry, Neuropsychology, and Behavioral Neurology, 1(2), 111-118.

Caamaño-Isorna, Francisco, Corral, Montserrat, Montes-Martínez, Agustín, \& Takkouche, Bahi. (2006). Education and dementia: a meta-analytic study. Neuroepidemiology, 26(4), 226232. https://doi.org/10.1159/000093378

Cabeza, R., Anderson, N. D., Locantore, J. K., \& McIntosh, A. R. (2002). Aging gracefully: compensatory brain activity in high-performing older adults. NeuroImage, 17(3), 13941402. https://doi.org/10.1006/nimg.2002.1280

Cantu, Phillip A, Hayward, Mark D, Hummer, Robert A, \& Chiu, Chi-Tsun. (2013). New estimates of racial/ethnic differences in life expectancy with chronic morbidity and functional loss: Evidence from the National Health Interview Survey. Journal of CrossCultural Gerontology, 28(3), 283-297. https://doi.org/10.1007/s10823-013-9206-5

Caunca, M. R., Odden, M. C., Glymour, M. M., Elfassy, T., Kershaw, K. N., Sidney, S., . . Zeki Al Hazzouri, A. (2020). Association of racial residential segregation throughout young adulthood and cognitive performance in middle-aged participants in the CARDIA Study. JAMA Neurol. https://doi.org/10.1001/jamaneurol.2020.0860

Chien, Sandy, Campbell, Nancy, Hayden, Orla, Hurd, Michael, Main, Regan, Mallett, Josh, .. . Moldoff, Michael. (2015). RAND HRS data documentation, version N. RAND Corporation.

Crimmins, E, Saito, Y, \& Kim, J. (2016). Change in Cognitively Healthy and Cognitively Impaired Life Expectancy in the United States: 2000-2010. SSM Population Health, 2, 793-797. https://doi.org/10.1016/j.ssmph.2016.10.007 
Crimmins, E, \& Zhang, Y. (2019). Aging Populations, Mortality, and Life Expectancy. Annual Review of Sociology, 45(1), 69-89. https://doi.org/10.1146/annurev-soc-073117-041351

Crimmins, E. M., Saito, Y., Kim, J. K., Zhang, Y. S., Sasson, I., \& Hayward, M. D. (2018). Educational Differences in the Prevalence of Dementia and Life Expectancy with Dementia: Changes from 2000 to 2010. The Journals of Gerontology Series B: Psychological Sciences and Social Sciences, 73(suppl_1), S20-S28. https://doi.org/10.1093/geronb/gbx 135

Crimmins, Eileen M, Kim, Jung Ki, Langa, Kenneth M, \& Weir, David R. (2011). Assessment of cognition using surveys and neuropsychological assessment: the Health and Retirement Study and the Aging, Demographics, and Memory Study. The Journals of Gerontology Series B: Psychological Sciences and Social Sciences, 66(suppl_1), i162-i171. https://doi.org/10.1093/geronb/gbr048

Dubois, M. F., \& Hebert, R. (2006). Cognitive-impairment-free life expectancy for Canadian seniors. Dementia and Geriatric Cognitive Disorders, 22(4), 327-333. https://doi.org/10.1159/000095593

Farina, Mateo P, Hayward, Mark D, Kim, Jung Ki, \& Crimmins, Eileen M. (2019). Racial and educational disparities in dementia and dementia-free life expectancy. The Journals of Gerontology Series B: Psychological Sciences and Social Sciences,.

Garcia, M, Saenz, J, Downer, B, \& Wong, R. (2018). The role of education in the association between race/ethnicity/nativity, cognitive impairment, and dementia among older adults in the United States. Demographic Research, 38, 155-168. https://doi.org/10.4054/demres.2018.38.6 
Garcia, Marc A, Ortiz, Kasim, Arévalo, Sandra P, Diminich, Erica D, Briceño, Emily, Vega, Irving E, \& Tarraf, Wassim. (2020). Age of migration and cognitive function among older Latinos in the United States. Journal of Alzheimer's Disease, 1-19. Advance online publication. https://doi.org/10.3233/JAD-191296

Garcia, Marc A., Downer, Brian, Chiu, Chi-Tsun, Saenz, Joseph L., Rote, Sunshine, \& Wong, Rebeca. (2019). Racial/ethnic and nativity differences in cognitive life expectancies among older adults in the United States. The Gerontologist, 59(2), 281-289. https://doi.org/10.1093/geront/gnx 142

Gee, Gilbert C, \& Ford, Chandra L. (2011). Structural racism and health inequities: Old issues, new directions. Du Bois Review: Social Science Research on Race, 8(1), 115-132. https://doi.org/10.1017/S1742058X11000130

Gilsanz, P., Mayeda, E. R., Glymour, M. M., Quesenberry, C. P., Jr., Mungas, D., DeCarli, C. S., \& Whitmer, R. A. (2019). Birth in high infant mortality states and dementia risk in a cohort of elderly African American and White health care members. Alzheimer Disease and Associated Disorders, 33(1), 1-6. https://doi.org/10.1097/WAD.0000000000000270

Glymour, M. M., \& Manly, J. J. (2008). Lifecourse social conditions and racial and ethnic patterns of cognitive aging. Neuropsychological Reviews, 18(3), 223-254. https://doi.org/10.1007/s11065-008-9064-z

Gross, A. L., Mungas, D. M., Crane, P. K., Gibbons, L. E., MacKay-Brandt, A., Manly, J. J., .. . Jones, R. N. (2015). Effects of education and race on cognitive decline: An integrative study of generalizability versus study-specific results. Psychology and Aging, 30(4), 863880. https://doi.org/10.1037/pag0000032 
Hauser, R. M, \& Willis, R. J. (2004). Survey design and methodology in the Health and Retirement Study and the Wisconsin Longitudinal Study. Population and Development Review, 30, 209-235.

Jagger, C., Van Oyen, H., \& Robine, J.-M. (2014). Health expectancy calculation by the Sullivan method: a practical guide. Institute for Ageing, Newcastle University, Newcastle upon Tyne, United Kingdom.

Jean, K. R., Lindbergh, C. A., Mewborn, C. M., Robinson, T. L., Gogniat, M. A., \& Miller, L S. (2019). Education differentially buffers cognitive performance in black and white older adults. The Journals of Gerontology, Series B: Psychological Sciences and Social Sciences, 74(8), 1366-1375. https://doi.org/10.1093/geronb/gby116

Lariscy, J. T., Hummer, R. A., \& Hayward, M. D. (2015). Hispanic older adult mortality in the United States: New estimates and an assessment of factors shaping the Hispanic paradox. Demography, 52(1), 1-14. https://doi.org/10.1007/s13524-014-0357-y

Lievre, A., Alley, D., \& Crimmins, E. M. (2008). Educational differentials in life expectancy with cognitive impairment among the elderly in the United States. Journal of Aging and Health, 20(4), 456-477. https://doi.org/10.1177/0898264308315857

Manly, J. J., Jacobs, D. M, Touradji, P., Small, S. A, \& Stern, Y. (2002). Reading level attenuates differences in neuropsychological test performance between African American and White elders. Journal of the International Neuropsychological Society, 8(3), 341348. https://doi.org/10.1017/S1355617702813157

Mayeda, E. R., Glymour, M. M., Quesenberry, C. P., \& Whitmer, R. A. (2016). Inequalities in dementia incidence between six racial and ethnic groups over 14 years. Alzheimers \& Dementia, 12(3), 216-224. https://doi.org/10.1016/j.jalz.2015.12.007 
McLaughlin, S. J., Kim, S., Li, L. W., \& Zhang, J. (2020). Educational differences in trajectories and determinants of healthy ageing in midlife and older Americans. Maturitas, 134, 2128. doi: https://doi.org/10.1016/j.maturitas.2020.01.002

Meng, X., \& D'arcy, C. (2012). Education and dementia in the context of the cognitive reserve hypothesis: a systematic review with meta-analyses and qualitative analyses. PloS One, 7(6). doi: https://doi.org/10.1371/journal.pone.0038268

Merolla, D. M., \& Jackson, O. (2019). Structural racism as the fundamental cause of the academic achievement gap. Sociology Compass, 13(6), e12696. doi: https://doi.org/10.1111/soc4.12696

NCHS. (2018). The linkage of National Center for Health Statistics survey data to the National Death Index-2015 Linked Mortality File (LMF): Methodology overview and analytic considerations. Hyattsville, MD. https://www. cdc.gov/nchs/data/datalinkage/LMF2015_Methodology_Analytic_Considerations.pdf

Pager, D., \& Shepherd, H. (2008). The sociology of discrimination: Racial discrimination in employment, housing, credit, and consumer markets. Annual Reviews of Sociology, 34, 181-209. https://doi.org/10.1146/annurev.soc.33.040406.131740

Peterson, R. L., Fain, M. J., A. Butler, E., Ehiri, J. E., \& Carvajal, S. C. (2020). The role of social and behavioral risk factors in explaining racial disparities in age-related cognitive impairment: a structured narrative review. Aging, Neuropsychology, and Cognition, 27(2), 173-196. https://doi.org/10.1080/13825585.2019.1598539

Phelan, J. C., \& Link, B. G. (2015). Is racism a fundamental cause of inequalities in health? Annual Review of Sociology, 41, 311-330. https://doi.org/10.1146/annurev-soc-073014$\underline{112305}$ 
Robitaille, A., van den Hout, A., Machado, R. J. M., Bennett, D. A., Cukic, I., Deary, I. J., . . Muniz Terrera, G. (2018). Transitions across cognitive states and death among older adults in relation to education: A multistate survival model using data from six longitudinal studies. Alzheimers \& Dementia. https://doi.org/10.1016/j.jalz.2017.10.003

Serra, L., Caltagirone, C., \& Bozzali, M. (2017). Cognitive reserve: the evolution of the conceptual framework. Journal of Systems and Integrative Neuroscience, 3(3), 1-6. https://doi.org/10.15761/jsin.1000159

Shkolnikov, V. M., Jdanov, D. A., Andreev, E. M., \& Vaupel, J. W. (2011). Steep Increase in Best-Practice Cohort Life Expectancy. Population and Development Review, 37(3), 419434. https://doi.org/10.1111/j.1728-4457.2011.00428.x

Sisco, S., Gross, A. L., Shih, R. A., Sachs, B. C., Glymour, M. M., Bangen, K. J, . . Manly, J. J. (2014). The role of early-life educational quality and literacy in explaining racial disparities in cognition in late life. The Journals of Gerontology Series B: Psychological Sciences and Social Sciences, 70(4), 557-567. https://doi.org/10.1093/geronb/gbt133

Soldan, A., Pettigrew, C., Cai, Q., Wang, J., Wang, M.-C., Moghekar, A., . . BIOCARD Research Team. (2017). Cognitive reserve and long-term change in cognition in aging and preclinical Alzheimer's disease. Neurobiology of Aging, 60, 164-172. https://doi.org/10.1016/j.neurobiolaging.2017.09.002

Sonnega, A., Faul, J. D., Ofstedal, M. B., Langa, K. M., Phillips, J. W. R., \& Weir, D. R. (2014). Cohort profile: the Health and Retirement Study (HRS). International Journal of Epidemiology, 43(2), 576-585. https://doi.org/10.1093/ije/dyu067

Steffener, Jason, Reuben, Aaron, Rakitin, Brian C, \& Stern, Yaakov. (2011). Supporting performance in the face of age-related neural changes: Testing mechanistic roles of 
cognitive reserve. Brain Imaging and Behavior, 5(3), 212-221.

https://doi.org/10.1007/s11682-011-9125-4

Stern, Y. (2002). What is cognitive reserve? Theory and research application of the reserve concept. Journal of the International Neuropsychological Society, 8(3), 448-460. https://doi.org/10.1017/S1355617702813248

Stern, Y. (2009). Cognitive reserve. Neuropsychologia, 47(10), 2015-2028. https://doi.org/10.1016/j.neuropsychologia.2009.03.004

Stern, Y. (2012). Cognitive reserve in ageing and Alzheimer's disease. The Lancet Neurology, 11(11), 1006-1012. https://doi.org/10.1016/S1474-4422(12)70191-6

Stern, Y. (2017). An approach to studying the neural correlates of reserve. Brain Imaging and Behavior, 11(2), 410-416. https://doi.org/10.1007\%2Fs11682-016-9566-X

Stern, Y., Arenaza-Urquijo, E. M., Bartrés-Faz, D., Belleville, S., Cantilon, M., Chetelat, G., .. . Kremen, W. S. (2018). Whitepaper: Defining and investigating cognitive reserve, brain reserve, and brain maintenance. Alzheimer's \& Dementia. Advance online publication. https://doi.org/10.1016/j.jalz.2018.07.219

Sullivan, D. F. (1971). A single index of mortality and morbidity. HSMHA Health Reports, $86(4), 347-354$.

U.S. Census Bureau. (2019, February 12, 2019). Educational Attainment in the United States: 2018. 2018 Annual Social and Economic Supplement. https://www.census.gov/data/tables/2018/demo/education-attainment/cps-detailed$\underline{\text { tables.html }}$

Zahodne, L. B., Glymour, M. M., Sparks, C., Bontempo, D., Dixon, R. A., MacDonald, S. W. S., \& Manly, J. J. (2011). Education does not slow cognitive decline with aging: 12-year 
evidence from the Victoria Longitudinal Study. Journal of the International Neuropsychological Society, 17, 1-8. http://doi.org/10.1017/S1355617711001044

Zissimopoulos, J. M, Tysinger, B. C, St. Clair, P. A, \& Crimmins, E. M. (2018). The impact of changes in population health and mortality on future prevalence of Alzheimer's disease and other dementias in the United States. The Journals of Gerontology Series B:

Psychological Sciences and Social Sciences, 73(suppl_1), S38-S47.

https://doi.org/10.1093/geronb/gbx147 
Table 1. Educational Attainment and Cognitive Status by Race/Ethnicity, Nativity, and Gender.

\begin{tabular}{|c|c|c|c|c|}
\hline & Whites & Blacks & US Hispanics & FB Hispanic \\
\hline \multicolumn{5}{|l|}{ Panel A: Women } \\
\hline Age & $66.9(10.6)$ & $65.2(10.1)^{*}$ & $64.9(10.1)^{*}$ & $64.6(9.7)^{*}$ \\
\hline \multicolumn{5}{|l|}{ Education } \\
\hline Less than HS & 14.4 & $32.6^{*}$ & $46.9^{*}$ & $67.9^{*}$ \\
\hline High School & 37.5 & $29.3 *$ & $28.1 *$ & $14.0 *$ \\
\hline Some College or More & 48.1 & $38.1 *$ & $25.0^{*}$ & $18.1 *$ \\
\hline \multicolumn{5}{|l|}{ Cognitive Status } \\
\hline Normal & 85.8 & $63.5^{*}$ & $65.9 *$ & $61.2^{*}$ \\
\hline CIND & 10.8 & $26.3 *$ & $24.3^{*}$ & $28.6^{*}$ \\
\hline Dementia & 3.4 & $10.2^{*}$ & $9.8^{*}$ & $10.2 *$ \\
\hline $\mathrm{N}$ & 69,130 & 16,445 & 4,045 & 5,843 \\
\hline
\end{tabular}

\section{Panel B: Men}

Age

65.5 (9.9)

$63.9(9.2)^{*}$

$63.6(8.6)^{*}$

$63.5(9.4)^{*}$

Education

Less than HS

14.5

$34.7^{*}$

$39.4 *$

$63.3^{*}$

High School

29.7

$28.9^{*}$

$25.5^{*}$

$14.4^{*}$ 


\section{Cognitive Status}

Normal

CIND

Dementia

$\mathrm{N}$

\section{7}

12.2

3.0

51,523
$61.8^{*}$

$28.3 *$

$9.9 *$

9,796
69.6*

$66.2 *$

$23.3^{*}$ $26.9^{*}$

$7.1 *$

$6.9^{*}$

4,133

Source: Health and Retirement Study, 1998-2014 (N=163,912).

Note: Unweighted N's; weighted percentages and means; CIND=cognitive impairment/no dementia; HS= high school; FB=foreign-born.

Reference $=$ White. ${ }^{*} \mathrm{p}<.05$. 
Table 2. Racial/Ethnic and Nativity Cognitive Health Life Expectancies Among Women at age 50 by Educational Attainment.

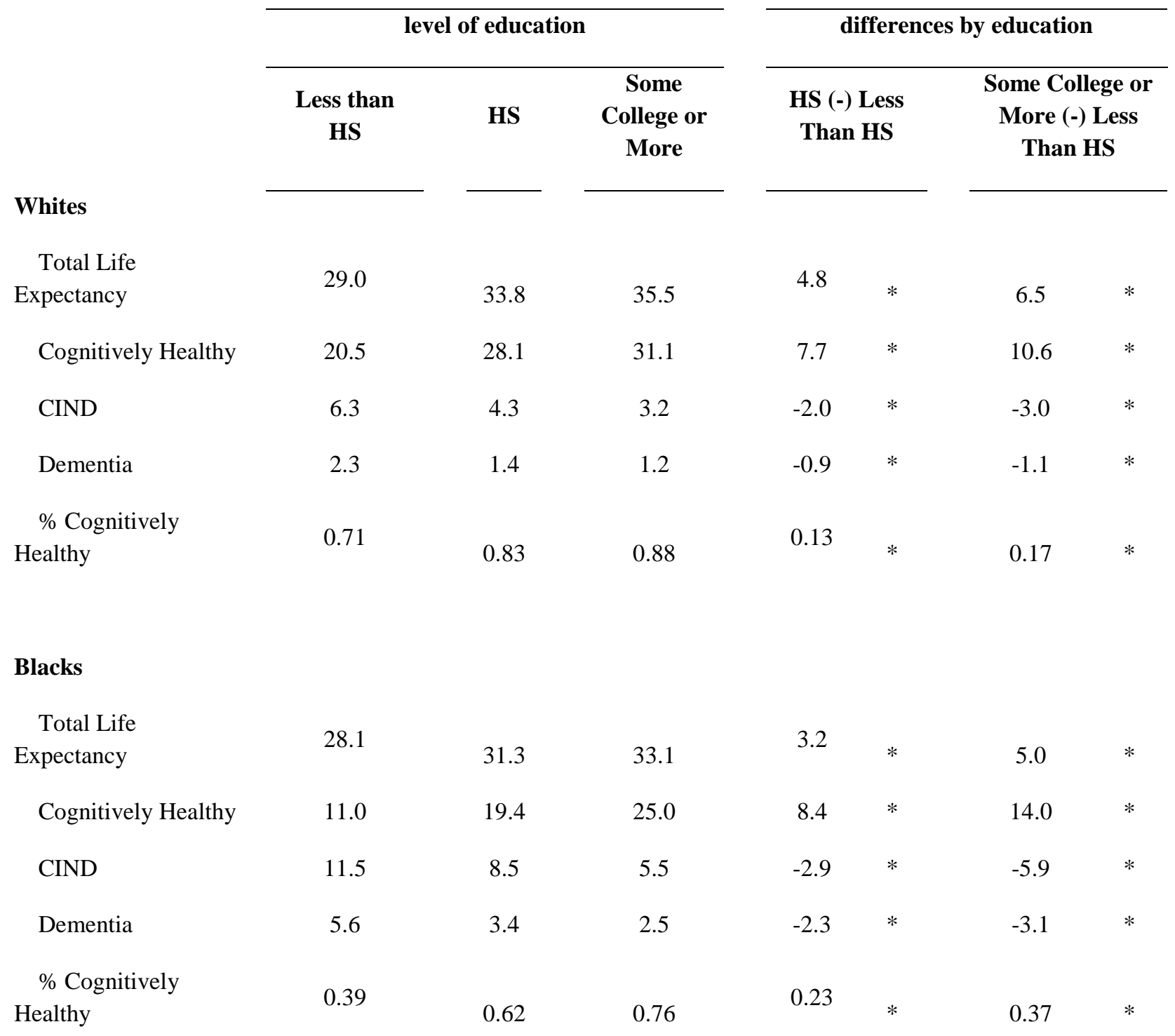

\section{U.S.-Hispanics}

Total Life

Expectancy

32.7

35.1

36.7

15.6

25.3

31.2

7.2

5.1

$2.5 *$

$9.6 *$

$-3.6 *$

$4.0 \quad *$

$15.5 *$

$-5.7 *$ 


\begin{tabular}{|c|c|c|c|c|c|c|c|}
\hline Dementia & 6.3 & 2.7 & 0.5 & -3.6 & $*$ & -5.8 & * \\
\hline $\begin{array}{l}\% \text { Cognitively } \\
\text { Healthy }\end{array}$ & 0.48 & 0.72 & 0.85 & 0.24 & $*$ & 0.37 & $*$ \\
\hline \multicolumn{8}{|l|}{ FB-Hispanics } \\
\hline $\begin{array}{l}\text { Total Life } \\
\text { Expectancy }\end{array}$ & 35.9 & 37.0 & 38.0 & 1.1 & & 2.1 & $*$ \\
\hline Cognitively Healthy & 15.8 & 26.1 & 27.3 & 10.3 & $*$ & 11.5 & $*$ \\
\hline CIND & 12.5 & 7.6 & 7.1 & -4.9 & $*$ & -5.4 & * \\
\hline Dementia & 7.6 & 3.3 & 3.5 & -4.3 & $*$ & -4.1 & * \\
\hline $\begin{array}{l}\% \text { Cognitively } \\
\text { Healthy }\end{array}$ & 0.44 & 0.71 & 0.72 & 0.27 & $*$ & 0.28 & $*$ \\
\hline
\end{tabular}

Source: Health and Retirement Study, 1998-2014. National Health Interview Survey Linked Mortality, 1999-2014 (with mortality follow-up to 2015).

Note: Ref=Less than HS; FB= foreign-born; * $\mathrm{p}<.05$. 
Table 3. Racial/Ethnic and Nativity Cognitive Health Life Expectancies Among Men at age 50 by Educational Attainment.

\begin{tabular}{|c|c|c|c|c|c|c|c|}
\hline \multirow{2}{*}{ Whites } & \multicolumn{3}{|c|}{ level of education } & \multicolumn{4}{|c|}{ differences by education } \\
\hline & $\begin{array}{c}\text { Less than } \\
\text { HS }\end{array}$ & HS & $\begin{array}{c}\text { Some } \\
\text { College or } \\
\text { More }\end{array}$ & $\begin{array}{r}\text { HS (-) } \\
\text { Than }\end{array}$ & & $\begin{array}{r}\text { Some ( } \\
\text { More } \\
\text { Th }\end{array}$ & $\begin{array}{l}\text { es or } \\
\text { ess }\end{array}$ \\
\hline Total Life Expectancy & 24.9 & 29.5 & 31.7 & 4.5 & $*$ & 6.7 & $*$ \\
\hline Cognitively Healthy & 16.1 & 24.1 & 28.2 & 8.0 & $*$ & 12.2 & $*$ \\
\hline CIND & 6.8 & 4.5 & 2.8 & -2.4 & $*$ & -4.1 & $*$ \\
\hline Dementia & 2.0 & 0.9 & 0.7 & -1.1 & $*$ & -1.4 & $*$ \\
\hline $\begin{array}{l}\% \text { Cognitively } \\
\text { Healthy }\end{array}$ & 0.64 & 0.82 & 0.89 & 0.17 & $*$ & 0.25 & $*$ \\
\hline
\end{tabular}

Blacks

\begin{tabular}{|c|c|c|c|c|c|c|}
\hline Total Life Expectancy & 23.8 & 26.9 & 29.0 & 3.1 & $*$ & 5.2 \\
\hline Cognitively Healthy & 10.0 & 16.3 & 22.3 & 6.3 & $*$ & 12.3 \\
\hline CIND & 9.4 & 8.4 & 5.5 & -1.0 & & -3.9 \\
\hline Dementia & 4.4 & 2.2 & 1.1 & -2.2 & $*$ & -3.2 \\
\hline $\begin{array}{l}\text { \% Cognitively } \\
\text { Healthy }\end{array}$ & 0.42 & 0.61 & 0.77 & 0.18 & $*$ & 0.35 \\
\hline \multicolumn{7}{|l|}{ U.S.-Hispanics } \\
\hline Total Life Expectancy & 27.5 & 31.0 & 32.3 & 3.6 & $*$ & 4.9 \\
\hline Cognitively Healthy & 14.3 & 19.0 & 23.8 & 4.7 & $*$ & 9.4 \\
\hline CIND & 9.0 & 8.6 & 4.4 & -0.4 & & -4.5 \\
\hline Dementia & 4.1 & 3.4 & 4.1 & -0.8 & & -0.01 \\
\hline
\end{tabular}


$\%$ Cognitively

Healthy

0.52

0.61

0.74

$0.09 *$

$0.21 *$

\section{FB-Hispanics}

\begin{tabular}{|c|c|c|c|c|c|c|c|}
\hline Total Life Expectancy & 31.2 & 33.4 & 33.6 & 2.2 & $*$ & 2.3 & * \\
\hline Cognitively Healthy & 16.3 & 22.5 & 26.9 & 6.2 & $*$ & 10.6 & * \\
\hline CIND & 10.7 & 7.9 & 4.9 & -2.8 & & -5.8 & $*$ \\
\hline Dementia & 4.3 & 3.1 & 1.7 & -1.2 & & -2.6 & $*$ \\
\hline $\begin{array}{l}\text { \% Cognitively } \\
\text { Healthy }\end{array}$ & 0.52 & 0.67 & 0.80 & 0.15 & $*$ & 0.28 & $*$ \\
\hline
\end{tabular}

Source: Health and Retirement Study, 1998-2014. National Health Interview Survey Linked Mortality, 1999-2014 (with mortality follow-up to 2015).

Note: Ref=Less than HS; FB= foreign-born; * $\mathrm{p}<.05$. 
Figure 1: Racial/Ethnic and Nativity Cognitive Life Expectancies among Women at age 50 by Educational Attainment.

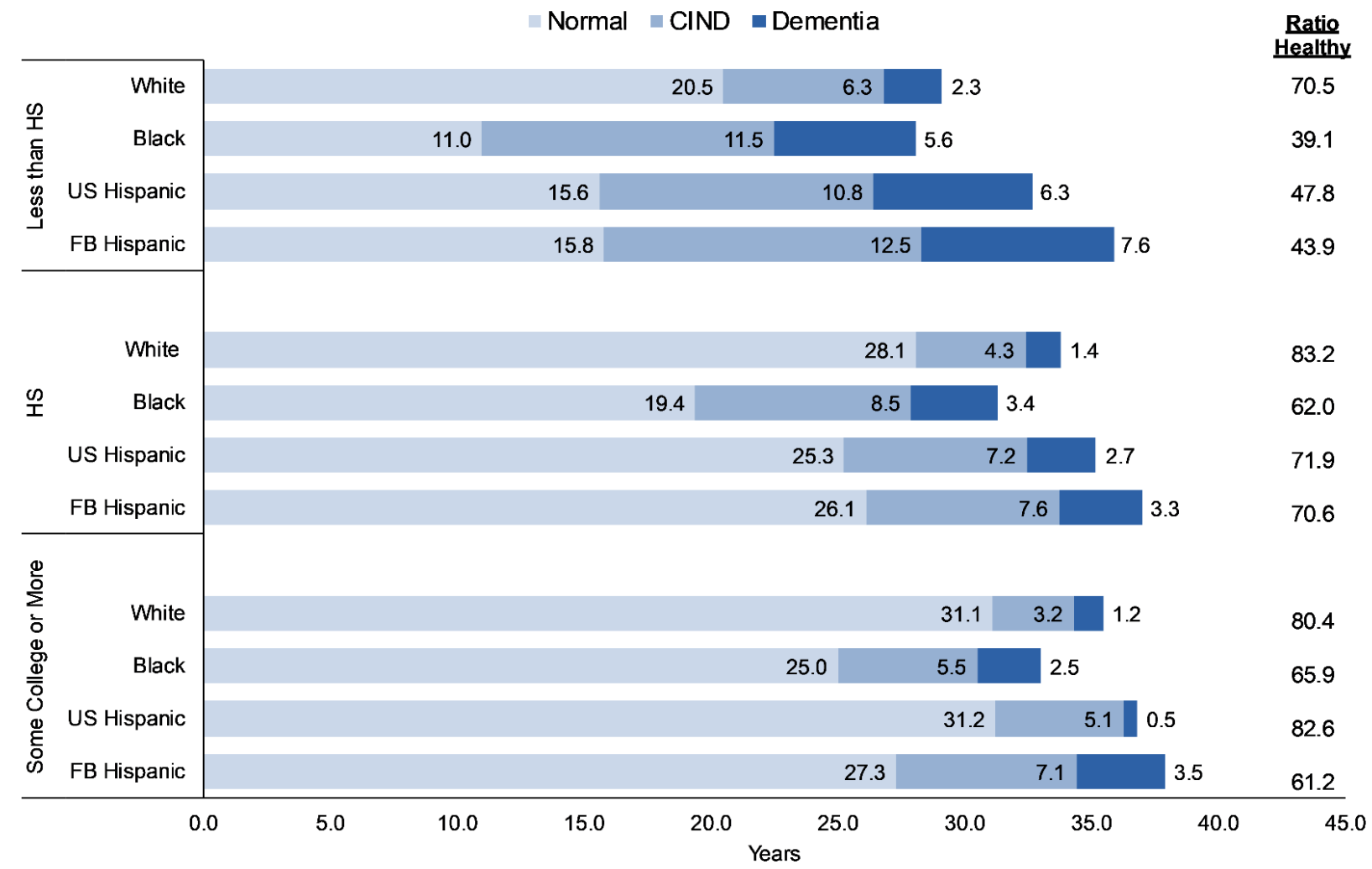


Figure 2. Racial/Ethnic and Nativity Cognitive Life Expectancies among Men at age 50 by Educational Attainment.

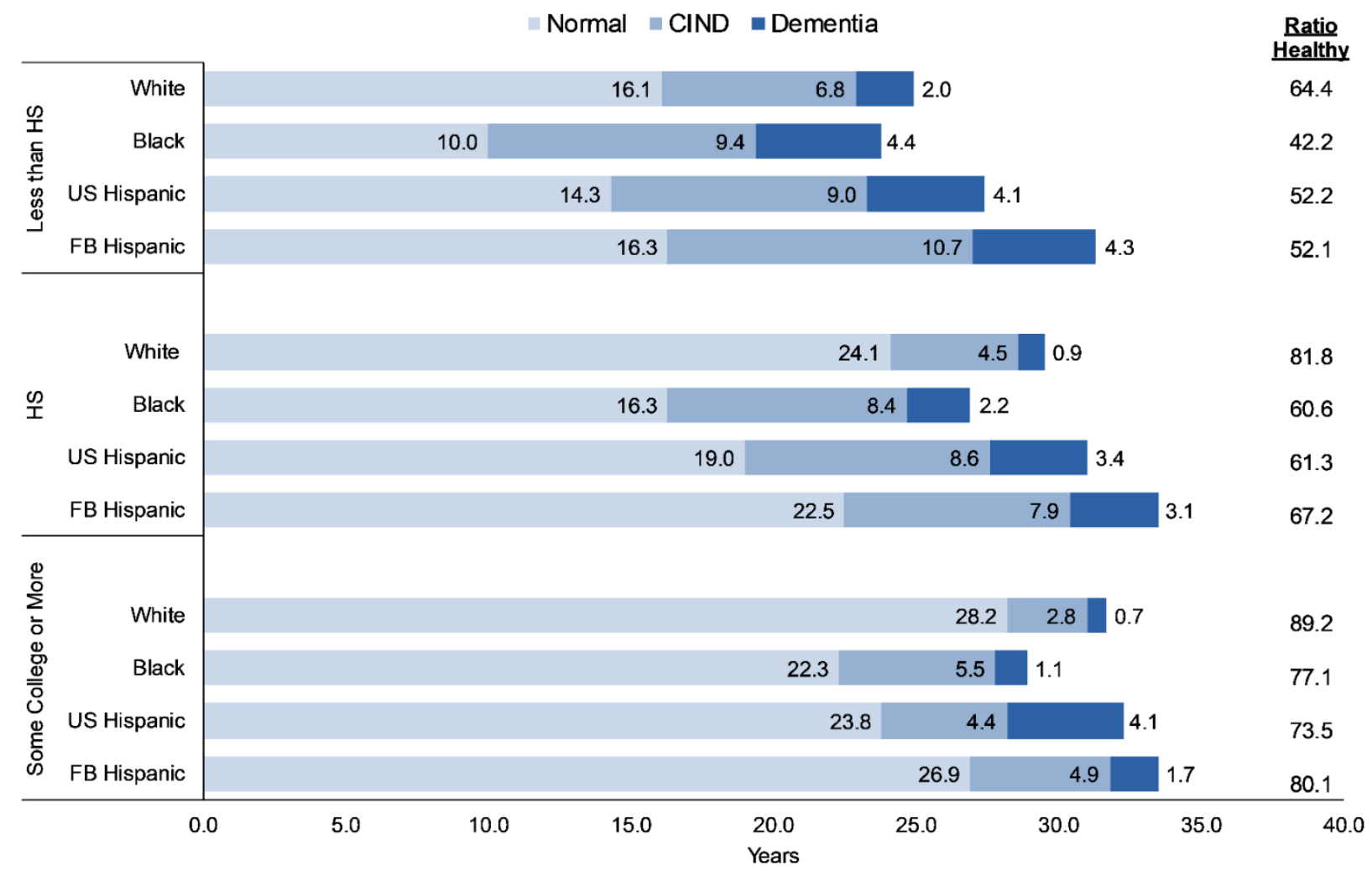

